\title{
Hyaloperonospora camelinae on Camelina sativa in Washington State: Detection, Seed Transmission, and Chemical Control
}

E. M. Babiker and S. H. Hulbert, Department of Plant Pathology, Washington State University, Pullman 99164-6430; and T. C. Paulitz, United States Department of Agriculture-Agricultural Research Service, Root Disease and Biological Control Research Unit, Pullman, WA 99164-6430

\begin{abstract}
Babiker, E. M., Hulbert, S. H., and Paulitz. T. C. 2012. Hyaloperonospora camelinae on Camelina sativa in Washington State: Detection, seed transmission, and chemical control. Plant Dis. 96:1670-1674.

Camelina (Camelina sativa) plants with symptoms of downy mildew were obtained from three different locations in Washington State. Based on polymerase chain reaction (PCR) and sequencing of the internal transcribed spacer (ITS)1-5.8S-ITS2 region, the causal pathogen was identified as Hyaloperonospora camelinae. The PCR primers consistently amplified 699-bp bands from the infected plants but not from the asymptomatic plants. A comparison of the sequences with those in GenBank revealed $100 \%$ sequence similarity to $H$. camelinae. Growth and development of the H. camelinae was observed in different tissues using light microscopy and scanning electron microscopy

(SEM). Light microscopic observation revealed the presence of oospores in the infected leaves and SEM revealed the presence of conidia and conidiophores on the seed surface. To determine whether $\mathrm{H}$. camelinae is a seed-transmitted pathogen, seed collected from infected plants were planted in Sunshine professional growing mix maintained in a growth chamber. Disease symptoms were observed in $96 \%$ of the seedlings compared with $3 \%$ of the seedlings grown from seed from asymptomatic plants, which indicates that $H$. camelinae is a seed-transmitted pathogen. Seed treated with mefenoxam, a fungicide specific for Oomycetes, significantly reduced the incidence of the disease.
\end{abstract}

Camelina (Camelina sativa (L.) Crantz) is an oilseed crop in the mustard family that has been cultivated in Europe since antiquity (19). It was more widely cultivated in Europe before World War II, and was introduced into North America as a weed in the 18th century, going by the name of false flax or gold-of-pleasure (7). Several characteristics have resulted in a renewed interest in camelina as an oilseed crop: its ability to grow in a dry climate (11), low nutrient requirements, and oil high in omega-3 fatty acids (9), which have health benefits (14). Recent interest in the crop as a biofuel feedstock has also stimulated research for both biodiesel and aviation fuel (26). It was investigated as an oilseed crop in Canada in the 1960s and in Minnesota in the 1980s (21). Within the last 5 years, this crop has been grown on limited commercial acreage in the low-rainfall regions of Montana and the inland $\mathrm{Pa}-$ cific Northwest (PNW) $(16,17)$.

Camelina can be attacked by a number of diseases and pests, including downy mildew (25). Peronospora camelinae was described by Gäumann in 1918, from a previously described taxon, $P$. pararsitica var. camelinae, described by Kühn in 1864 (23). There were reports of both $P$. parasitica and $P$. camelinae on camelina in Europe in the mid-20th century $(3,5)$, and both have been reported from Poland, Austria, Switzerland, Spain, Portugal, Bulgaria, and Germany (6). The first report of downy mildew on camelina in $\mathrm{N}$. America was from Canada in 1955 (2). Prior to the 2000s, there was no report of this disease from the United States in plant pathology literature but it was recently reported from Oregon and the high plains of the United States in 2009 and 2011 (10,20). Both $P$. camelinae and $P$. parasitica were recently moved to the genus Hyaloperonospora (4).

Since spring 2010, there has been an increase in incidence and severity of downy mildew disease in different locations in Wash-

Corresponding author: S. H. Hulbert, E-mail: scot_hulbert@wsu.edu

Accepted for publication 4 June 2012.

http://dx.doi.org/10.1094/PDIS-02-12-0212-RE

This article is in the public domain and not copyrightable. It may be freely reprinted with customary crediting of the source. The American Phytopathological Society, 2012. ington State. Disease symptoms appeared as white mycelial growth on stems and developing pods, twisted stems, poor flowering, and empty pods (25). Chlorotic lesions were occasionally seen on leaves. The distinction of Hyaloperonospora spp. based on morphological characteristics is laborious, time consuming, and likely less reliable than molecular analyses. Therefore, an improved method of detection using a polymerase chain reaction (PCR)-based assay is needed because both Hyaloperonospora camelinae and $H$. parasitica are obligate parasites that grow only on living hosts. PCR approaches have been successfully used to detect the presence of fungal and Oomycete pathogens in plant tissues $(18,22)$. Recently, the sequences of the complete ITS15.8S-ITS2 region of $H$. camelinae and $H$. parasitica have become available (8). This sequence can be used to design species-specific primers to detect the presence of either of $H$. camelinae and $H$. parasitica in plant tissues.

The incidence of downy mildew in fields with no previous history of camelina raises the question of whether $H$. camelinae is seed transmitted or not. Transmission of $H$. camelinae through seed has not been documented. Infected seed could be a main source of inoculum, especially in areas where the pathogen does not exist, and, thereby, extend the geographical distribution of the disease. To develop effective management strategies for downy mildew, it is important to know whether $H$. camelinae is seed transmitted or not, and how effective a seed treatment would be. Little research has been done on seed treatments for this crop. Mefenoxam seed treatment has been found to be effective in reducing the incidence of downy mildew in sunflower and pearl millet $(22,27)$. The efficacy of mefenoxam for controlling $H$. camelinae has not been investigated. Therefore the objectives of this study were to (i) identify the downy mildew pathogen of camelina in Washington State, (ii) develop a reliable PCR-based assay to detect the presence of the pathogen in the seed, (iii) determine whether $H$. camelinae is a seed transmitted pathogen, and (iv) test the efficacy of mefenoxam as a seed treatment for controlling downy mildew of camelina.

\section{Materials and Methods}

Design of $\boldsymbol{H}$. camelinae- and $\boldsymbol{H}$. parasitica-specific primers. The sequences of the ITS1-5.8S-ITS2 region of $H$. camelinae 
(EU049217) and H. parasitica (EU049279) were obtained from GenBank (National Center for Biotechnology Information, http://www.ncbi.nlm.nih.gov). The ITS sequences from the two species were aligned using CLUSTAL $\mathrm{W}$ in BioEdit 4.0.6.2 (http://www.mbio.ncsu.edu/BioEdit/page2.html) and three specific PCR primers were designed from nonconserved regions to amplify 802 and 584 bp from $H$. parasitica and 699 bp from $H$. camelinae. (Table 1).

PCR assays using $\boldsymbol{H}$. camelinae-specific primers. Samples of diseased camelina plants were collected from three different locations in Washington State, near Lind, Dusty, and Pullman. The genomic DNA was extracted from the fungus mycelium that was carefully removed from the infected plants using a sterile blade, and about $0.2 \mathrm{~g}$ of the collected mycelia were placed in $1.5-\mathrm{ml}$ Eppendorf tubes and ground in liquid nitrogen. Following grinding, $500 \mu \mathrm{l}$ of warm DNA extraction buffer $(100 \mathrm{mM}$ Tris- $\mathrm{HCl}, 20$ $\mathrm{mM}$ EDTA, $2 \mathrm{M} \mathrm{NaCl}, 2 \%$ cetyltrimethylammonium bromide, and $0.3 \% \mathrm{NaHSO}_{3}[\mathrm{pH} 8.0]$ ) was added and mixed. The tubes were incubated in a water bath at $65^{\circ} \mathrm{C}$ for $45 \mathrm{~min}$, with hand agitation every $5 \mathrm{~min}$. After incubation, $500 \mu \mathrm{l}$ of chloroform: isoamyl alcohol $(24: 1, \mathrm{vol} / \mathrm{vol})$ was added to the tubes and the contents were mixed and centrifuged at $10,000 \times g$ for $5 \mathrm{~min}$. The supernatant was transferred to a new tube and an equal volume of isopropyl alcohol was added. The tubes were inverted gently, incubated for 5 $\min$ at $-20^{\circ} \mathrm{C}$, and centrifuged at $10,000 \times g$ for $5 \mathrm{~min}$ at $4^{\circ} \mathrm{C}$. After discarding the supernatant, the DNA pellet was washed in $500 \mu \mathrm{l}$ (70\%) of ethanol, air dried, and resuspended in $100 \mu$ l of water. For negative control, seed from asymptomatic plants were collected and placed in a beaker with $0.5 \%$ sodium hypochlorite $(\mathrm{NaOCl})$ and stirred with a magnetic stir bar for $5 \mathrm{~min}$. Seed were rinsed in water and planted in Sunshine professional growing mix, and 2week-old leaves were used for DNA extraction. The PCR reaction was carried out in $20-\mu \mathrm{l}$ volumes using $100 \mathrm{ng}$ of genomic DNA, $1 \times$ buffer, $1.5 \mathrm{Mm} \mathrm{MgCl}_{2}, 0.2 \mathrm{mM}$ each dNTP, $0.5 \mu \mathrm{M}$ each primer pair, and 1 unit of Taq polymerase. The PCR reactions were performed following $5 \mathrm{~min}$ of incubation at $94^{\circ} \mathrm{C}$ with 35 cycles of 1 min at $94^{\circ} \mathrm{C}, 1 \mathrm{~min}$ at $60^{\circ} \mathrm{C}$, and $1 \mathrm{~min}$ at $72^{\circ} \mathrm{C}$. A final extension of 7 min at $72^{\circ} \mathrm{C}$ was performed. PCR products were separated by electrophoresis in $1.5 \%(\mathrm{wt} / \mathrm{vol})$ agarose gels stained with ethidium bromide. The desired DNA fragments were recovered and purified by a QIAquick gel extraction kit (Qiagen, Inc.) following the manufacturer's protocol. The purified fragments were ligated to the pGEM-T easy vector system kit (Promega Corp.) and $4 \mu \mathrm{l}$ of the ligation mixture was transformed to $100 \mu \mathrm{l}$ of Escherichia coli strain TOP10. Based on the PCR results using HC and HP primer pairs, positive clones with the desired fragment were grown overnight on $2 \mathrm{ml}$ of liquid Luria-Bertani broth supplemented with ampicillin at $100 \mu \mathrm{g} \mathrm{ml}^{-1}$. Plasmid DNA was extracted using a Pure Yield plasmid miniprep kit (Promega Corp.). Recombinant clones were sent to Elim Biopharmaceutical Inc. for sequencing and a BLAST search was used to compare the obtained sequences with sequences in the GenBank database.

Detection and transmission of $\boldsymbol{H}$. camelinae. To investigate whether infected seed can give rise to infected camelina plants, seed from infected camelina plants were planted in tapered plastic cones ( $4 \mathrm{~cm}$ in diameter by $20 \mathrm{~cm}$ long; Ray Leach Cone-tainer) filled with Sunshine professional growing mix (SunGro). Cones were maintained in a growth chamber programmed for $12^{\circ} \mathrm{C}$ with a 12-h photoperiod and watered uniformly at 4-day intervals. High humidity was maintained by partially covering the 2-week-old seedlings with plastic for 6 weeks. At the flowering growth stage, plants were inspected for visual symptoms of downy mildew and the percentage of infected plants was calculated for each replicate. Leaf samples were collected from infected and asymptomatic plants for DNA extraction. The experiment was repeated twice and the data from repeated experiments were tested for equality of variance.

Effect of mefenoxam seed treatment on incidence of downy mildew. Seed from infected plants were treated with mefenoxam or rinsed with $0.5 \% \mathrm{NaOCl}$, stirred with a magnetic stir bar for 5 min, and then treated with mefenoxam. Mefenoxam (Apron XL at $3 \mathrm{~g}$ a.i./kg of seed; Syngenta Crop Protection, Inc.) was diluted in a volume of double-distilled water equivalent to $15 \%$ of seed weight. Seed were placed with the fungicide in a plastic bag and shaken for $1 \mathrm{~min}$. Treated seed were planted in cones filled with Sunshine professional growing mix. Control cones were planted using nontreated seed collected from the same infected plants. Seedlings were maintained in a growth chamber programmed as previously described. The experiment was repeated twice. Plants were inspected for visual symptoms of downy mildew at the flowering stage and the percentage of infected plants was calculated for each treatment.

Inoculation of canola with $\boldsymbol{H}$. camelinae. The pathogenicity of $H$. camelinae on canola was assessed in a growth chamber experiment. The conidial suspension was prepared by immersing infected leaves and stems in water for $24 \mathrm{~h}$ with shaking. The conidial concentration was quantified with a hemacytometer and adjusted to 5 $\times 10^{4}$ spores $/ \mathrm{ml}$. Healthy canola seedlings of 'Virginia' and 'Rossini' were inoculated by pipetting $500 \mu \mathrm{l}$ of conidial suspension of $H$. camelinae on the upper surface of the lower leaf. Asymptomatic camelina seedlings of 'Cheyenne' were inoculated and maintained in the same growth chamber as the control. In other experiments, seed of two canola cultivars, Virginia and 'Wichita', were germinated in two petri dishes with filter paper saturated with $2 \mathrm{ml}$ of conidial suspension of $H$. camelinae. The petri dishes were incubated in a growth chamber programmed for $12^{\circ} \mathrm{C}$ with a 12 -h photoperiod for 3 days and the germinated seed were then planted in plastic containers filled with Sunshine professional growing mix. The infected plants were maintained in a growth chamber at $15^{\circ} \mathrm{C}$ and loosely covered with plastic bags for 6 weeks. Plants were monitored visually for symptom development on leaves and microscopically examined for the growth of the pathogen.

Light and scanning electron microscopy. To verify the presence of conidiophores, conidia, and oospores in camelina leaves and seed coats, dry leaves and seed were soaked in water for 3 days with shaking. Small leaf and seed coat segments were floated on glass slides, covered with coverslips, pressed gently, and examined with a bright-field light microscope at $\times 40$.

Scanning electron microscopy (SEM) was used to examine the internal tissue of the infected camelina stems. Stems pieces were collected from infected seedlings and placed in a fixative solution consisting of $2.5 \%$ glutaraldehyde and $2 \%$ paraformaldehyde buffer. The specimens were then treated with $1 \%$ osmium tetraoxide for $1 \mathrm{~h}$ and dehydrated through a graded ethanol series for $10 \mathrm{~min}$ before critical point drying. The tissues were coated with gold and examined using the Hitachi S-570 electron microscope. Seed were collected from infected plants, lyophilized for 24 $\mathrm{h}$, and observed under field-emission SEM (Virtis Inc.).

Statistical analysis. Analysis of variance was calculated using Proc GLM in SAS (version 9.1; SAS Institute). Means were compared using Fisher's protected least significant difference at $P=$ 0.05 . A two-tailed $F$ test for equality of variances was used to test whether data from the trials could be combined and analyzed together.

Table 1. List of primer pairs designed for the amplification of the internal transcribed spacer (ITS)1-5.8S-ITS2 region from Hyaloperonospora camelinae and $H$. parasitica with the optimum annealing temperature

\begin{tabular}{lll}
\hline Primer & \multicolumn{1}{c}{ Sequence $\left(\mathbf{5}^{\prime} \rightarrow \mathbf{3}^{\prime}\right)$} & $\begin{array}{c}\text { Annealing } \\
\text { temperature }\left({ }^{\circ} \mathbf{C}\right)\end{array}$ \\
\hline $\begin{array}{l}\text { H. camelinae } \\
\text { HC-L }\end{array}$ & $\begin{array}{l}\text { attgggagtcgtgatcttgg } \\
\text { ctcgacaaccgaagttgaca }\end{array}$ \\
$\begin{array}{ll}\text { HC-R } \\
\text {. parasitica }\end{array}$ & 60 \\
HP1-L & gatcttggtggtaactactagtctcg & $\ldots$ \\
HP1-R & actggcctcacggacacac & 60 \\
HP2-L & gaaccattgggctttgtct & 60 \\
HP2-R & cttgccttacggacaccatt & $\ldots$ \\
\hline
\end{tabular}




\section{Results}

The HC primer pairs were used to detect the presence of $H$. camelinae in the infected plants. The HC primer pair amplified a 699-bp fragment from DNA extracted from infected plants collected at different locations but no amplification was detected from DNA extracted from asymptomatic plants. Comparison of the 645bp sequences with those in GenBank revealed that the sequences were $100 \%$ identical to $H$. camelinae sequences EU049217, AY531456, and AY531457 and 92\% similar to H. parasitica sequence EU049279. These results indicated that $H$. camelinae is the main cause of downy mildew in Washington State. The HP1 primer pair designed from the ITS1-5.8S-ITS2 region of $H$. parasitica weakly amplified an approximately 400-bp product from infected camelina plants collected from Lind. Comparison of the sequences with those in GenBank revealed that the sequence showed no similarity to the ITS1-5.8S-ITS2 region of $H$. parasitica and was apparently a nonspecific amplification product. When the HP2 primer pair and the combination of HP2L and HP1R were used they did not amplify any products. To evaluate the specificity of the $\mathrm{HC}$ primer pair, batches of infected and asymptomatic seed were separately germinated in petri dishes. The $\mathrm{HC}$ primer pair consistently amplified a 700-bp DNA fragment from plants grown from the infected seed only. To evaluate the sensitivity of the HC primer pair, 1, 10, and $100 \mathrm{ng}$ of DNA from infected plant material was used in a $20-\mu \mathrm{l}$ volume PCR mix. The HC primer pair amplified a visible product from 10 and $100 \mathrm{ng}$ of DNA in 35 cycles of amplification.

To examine the transmission of the pathogen, seed collected from infected camelina plants were planted in cones and maintained in the growth chamber programmed for $12^{\circ} \mathrm{C}$ with a $12-\mathrm{h}$ photoperiod. Two trials were conducted in two different growth chambers. According to two-tailed $F$ tests, variances from the two trials were not significantly different $(P=0.25)$; therefore, data from the two experiments were pooled and analyzed together. At the flowering stage, the incidence of downy mildew was statistically significant between plants grown from seed collected from infected camelina plants and plants grown from seed collected from asymptomatic plants $(P<0.0001)$. Approximately $96 \%$ of the seedlings (192 total) grown from the infected seed developed downy mildew symptoms. In contrast, only $3 \%$ of the seedlings from seed collected from asymptomatic plants in the same field developed symptoms. To confirm the presence of $H$. camelinae in the tissue, the HC designed primer pair was used with DNA extracted from the infected plants. The HC-designed primer pair amplified an approximately 700-bp fragment from each of seven of the infected plants tested and DNA sequencing confirmed the identity of the fragment as $H$. camelinae. Sequencing results revealed that all the amplified fragments were 99 to $100 \%$ identical to the ITS1-5.8S-ITS2 region of $H$. camelinae. SEM observation revealed that stems and seed were colonized by white-colored conidiophores and conidia (Fig. 1A and B). Most of the observed conidia were subglobose, hyaline, and measured 5 to 18.1 by 3 to $8.3 \mu \mathrm{m}$ (Fig. 1C and D). In addition, light-microscopic observation confirmed the presence of conidiophores, conidia, and oospores in camelina leaves but no oospores were observed on the seed surface (Fig. $1 \mathrm{E}$ and $\mathrm{F}$ ). These results indicated that $H$. camelinae is a seed-transmitted pathogen and care should be taken to reduce the spread of the pathogen.

The effect of seed treatment on incidence of downy mildew was studied. The treatment included nontreated infected seed, seed treated with mefenoxam only, and seed rinsed in $0.5 \%$ sodium hypochlorite and then treated with mefenoxam. Significantly lower incidence of downy mildew was observed when seed were treated with mefenoxam at $3 \mathrm{~g}$ a.i./kg of seed $(P<0.0001)$. Compared with seed treatment with mefenoxam, rinsing in $0.5 \%$ sodium hypochlorite and then treating with mefenoxam significantly reduced the incidence of the disease from 39.8 to $11.8(P<0.0001)$.

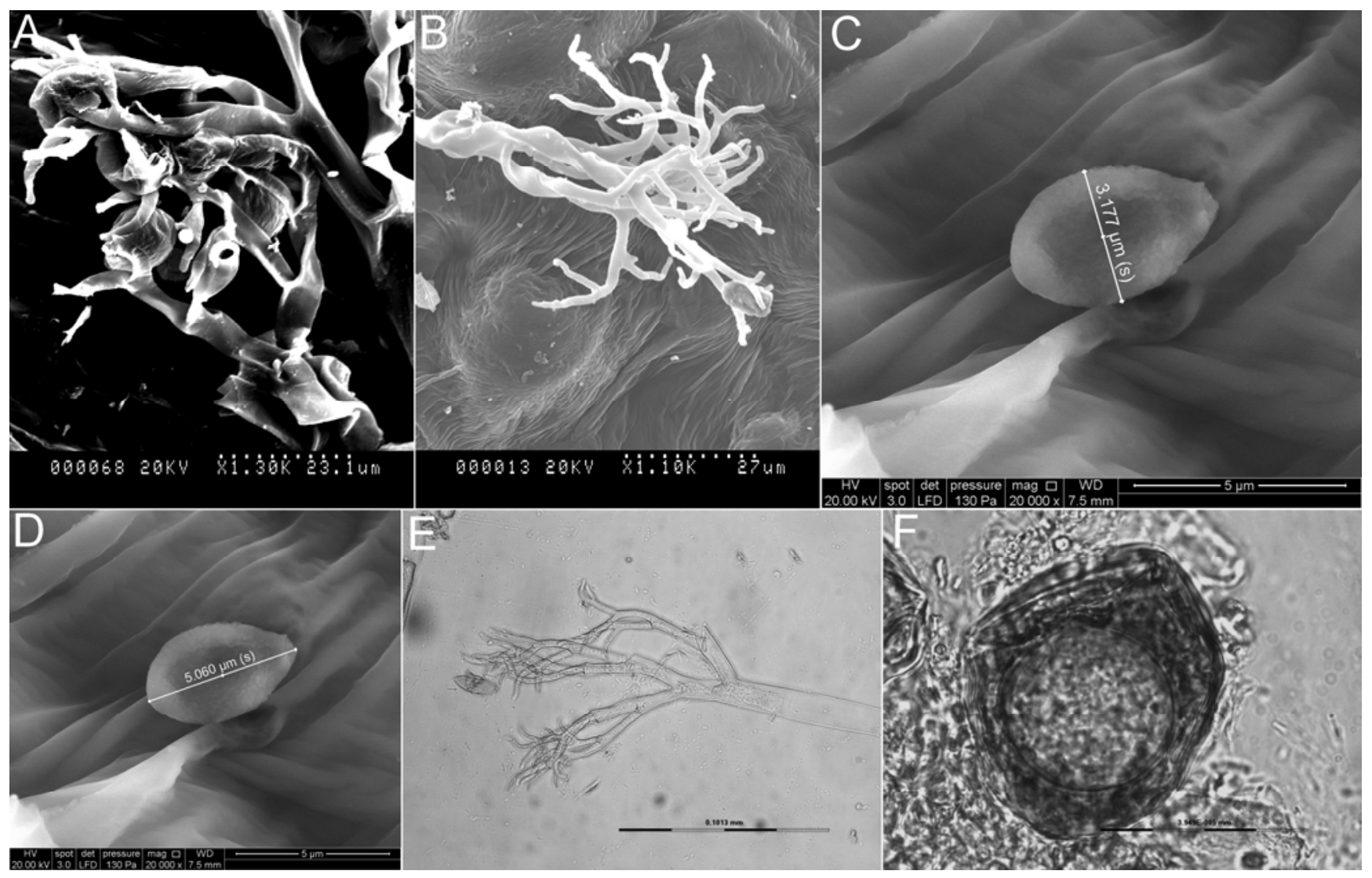

Fig. 1. Scanning electron micrograph of the $\mathbf{A}$, stem and $\mathbf{B}$, seed surface of camelina colonized by conidiophores of Hyaloperonospora camelinae. $\mathbf{C}$ and $\mathbf{D}$, Field emission scanning electron micrograph of conidia of $H$. camelinae on the surface of camelina seed. Light micrograph of $\mathbf{E}$, conidiophore and $\mathbf{F}$, oospores of $H$. camelinae in camelina leaf tissue. 
PCR assays using the HC-designed primer and sequence analysis confirmed the presence of $H$. camelinae in the infected plants. Artificial inoculation using inoculum prepared from infected plants indicated that $H$. camelinae was able to cause downy mildew on camelina but not in canola.

\section{Discussion}

Several previous studies have reported downy mildew on camelina caused by $H$. parasitica and $H$. camelinae $(10,20,25)$. PCR with universal ITS primers was used by Putnam et al. (20) and Harveson et al. (10) for identification but they had to sequence the products for verification. Because the sequences of the ITS region of the ribosomal RNA-encoding genes are quite different between the two species, it was relatively simple to design PCR primers that distinguished between the two species without sequencing. The HC primer pair designed from this region appeared suitable for $H$. camelinae detection because it did not yield PCR products from the asymptomatic plants. The HP primer pair weakly amplified an approximately 400-bp product from infected camelina plants collected from Lind but this appeared to be a nonspecific amplification product. These results indicated that $H$. camelinae is the causal pathogen of downy mildew on camelina in Washington State in recent years. To our knowledge, this is the first report of $H$. camelinae in Washington State. Using dilution series, we demonstrated that the HC primer pair is sufficiently sensitive to detect the presence of $H$. camelinae in plant tissue. The PCR assay was faster and less labor intensive than morphological examination, making it possible to screen a large number of samples in a single day.

Seed transmission of $H$. camelinae on camelina was speculated because there had been no previous reports of downy mildew in Washington State, the fields where the disease was observed had not been previously cropped with camelina, and no downy mildew symptoms were observed on other Brassica spp. Seed collected from infected plants were planted in cones filled with Sunshine professional growing mix and placed in isolated controlled-environment growth chambers to ensure the absence of any extraneous source of inoculum. Symptom development in the seedlings indicated that infected seed were the only source of inoculum. This finding was further supported by the observation of the conidia and conidiophores on the seed surface using SEM. In the literature of downy mildew pathogens, there are numerous reports of seed transmission. Landa et al. (13) reported that downy mildew of opium poppy caused by $P$. arborescens is a seed-transmitted disease. Peronosclerospora sorghi, the causal of the downy mildew of maize, was previously reported by Adenle and Cardwell (1) to be seed transmitted. Introducing infected seed would allow the pathogen to become established in camelina fields with no previous history of downy mildew and it may create a problem in subsequent camelina crops. Oospores were observed in infected leaves, and these could serve as a long-term survival structure in the soil. However, seed treatment with mefenoxam could be an adequate means of control, especially if seed were rinsed in $0.5 \%$ sodium hypochlorite before treatment. To our knowledge this is the first report on evaluating the effectiveness of mefenoxam as a seed treatment to control $H$. camelinae on camelina.

The epidemiology of this disease in Western United States is still unknown, but it may be similar to downy mildew of sunflower caused by Plasmopara halstedii. This pathogen is capable of infecting roots from oospores in soil, and was the first downy mildew to be demonstrated as a soilborne pathogen (24). P. halstedii can also infect the hypocotyl of emerging seedlings, either from inocula on the seed or oospores in the soil (24). The light-microscopy observation revealed the presence of oospores of $\mathrm{H}$. camelinae in leaves of camelina. When leaves decompose in the soil, oospores may be released and infect the subsequent camelina crop. This observation revealed the potential of plant debris serving as an inoculum source if leaves are harvested with seed or decompose in the field. In pearl millet downy mildew, the development of the symptoms on adult plants is due to either systemic mycelium or secondary infection (28). Mature tissue of many hosts become more resistant to infection, and the role of secondary infection by conidia is variable, depending on the environmental conditions and moisture (29). It is not known how important secondary spread would be in eastern Washington because, by the time conidia are produced, the conditions are warm and dry, and rainfall is rare in the summer.

Little work has been done on camelina downy mildew disease management. Polish researchers found that spraying with copper oxychloride and maneb were effective in reducing the disease $(33,34)$. The low economic value of the crop may preclude fungicide sprays but seed treatments may be economical. Response of downy mildew pathogens to metalaxyl and mefenoxam seed treatments was investigated in previous studies. Mefenoxam in conjunction with resistant genotype was found to be effective in controlling Peronosclerospora sorghi, the causal agent of downy mildew of sorghum $(12,30)$. Seed treatment with metalaxyl significantly reduced the incidence and severity of downy mildew of pearl millet compare to non treated seed (32).

Besides chemical control, resistant varieties may provide a sustainable control strategy in combination with seed treatment. In camelina, resistance to downy mildew was found to be effective in reducing the incidence of the disease $(15,31)$.

The results from this study indicated that $H$. camelinae is the causal pathogen of downy mildew on camelina and that the designed PCR primers can be used to detect the presence of $H$. camelinae in infected tissue. In addition, we demonstrated that $H$. camelinae is seed transmitted, meaning that seed can serve as a source of inoculum for future crops and dispersal to new areas. Mefenoxam seed treatment can reduce the incidence of downy mildew. Additional work is needed to determine how long the pathogen survives in or on the seed, whether seed infestation can be eliminated, and whether the oospores in soil and infected tissue could serve as inocula for the development of the disease in following crop.

\section{Acknowledgments}

We thank V. Lynch-Holm at Washington State University's Franceschi Microscopy and Imaging Center for her advice and technical assistance. We are grateful for support from the Washington State Department of Agriculture through the WSU Biofuels Cropping Systems Research and Extension Project.

\section{Literature Cited}

1. Adenle, V. O., and Cardwell, K. F. 2000. Seed transmission of maize downy mildew (Peronosclerospora sorghi) in Nigeria. Plant Pathol. 49:628-634.

2. Anonymous, 1955. Diseases of forage crops and other field crops. Can. Plant Dis. Surv. 35:52.

3. Borg, A. 1953. Pages 20-23 in: Some Further Parasitic Attacks on the Oil Camelina. Vaxtskyddsnotiser, Stockholm. 1953 Rev. Appl. Mycol. 32:100.

4. Constantinescu, O., and Fatehi J. 2002. Peronospora-like fungi (Chromista, Peronosporales) parasitic on Brassicaceae and related hosts. Nova Hedwigia 74:291-338.

5. Darpoux, H. 1945. Contribution à l'étude des maladies des plantes oléagineuses en France. Ann. Epiphyt. 11:71-103. 1946 Rev. Appl. Mycol 25:416.

6. Farr, D. F., and Rossman, A.Y. Fungal Databases, Systematic Mycology and Microbiology Laboratory, ARS, USDA. Retrieved September 5, 2012, from http://nt.ars-grin.gov/fungaldatabases/

7. Francis, A., and Warwick, I. 2009. The biology of Canadian weeds. 142. Camelina alyssum (Mill.) Thell.; C. microcarpa Andrz. ex DC.; C. sativa (L.) Crantz. Can. J. Plant Sci. 89:791-810.

8. Göker, M., Rithmüller, A., Voglmayr, H., Weiss, M., and Oberwinkler, F. 2004. Phylogeny of Hyaloperonospora based on nuclear ribosomal internal transcribed spacer sequences. Mycol. Prog. 3:83-94.

9. Gugel, R. K., and Falk, K. C. 2006. Agronomic and seed quality evaluation of Camelina sativa in western Canada. Can. J. Plant Sci. 86:1047-1058.

10. Harveson, R. M., Santra, D. K., Putnam, M. L., and Curtis, M. 2011. A new report for downy mildew [(Hyaloperonospora camelinae Gäum.) Göker, Voglmayr, Riethm., M. Weiss and Oberw. 2003] of camelina [Camelina sativa (L.) Crantz] in the High Plains of the United States. Plant Health Progress. Online publication. doi:10.1094/PHP-2011-1014-01-BR

11. Hunsaker, D. J., French, A. N., Clarke, T. R., and El-Shikha, D. M. 2011. Water use, crop coefficients, and irrigation management criteria for camelina production in arid regions. Irrig. Sci. 29:27-43.

12. Isakeit, T., and Jaster, J. 2005. Texas has a new pathotype of Peronosclerospora sorghi, the cause of sorghum downy mildew. Plant Dis. 89:529.

13. Landa B. B., Montes-Borrego, M., Muñoz-Ledesma F. J., and Jiménez- 
Díaz, R. M. 2005. First report of downy mildew of opium poppy caused by Peronospora arborescens in Spain. Plant Dis. 89:338.

14. Larsen, R., Eilertsen, K. E., and Elvevoll, E. O. 2011. Health benefits of marine foods and ingredients. Biotechnol. Adv. SI:508-518.

15. Li, J., Caldwell, C. D., Gray, A. B., and Falk, K. C. 2010. Evaluation of downy mildew resistance of 11 Camelina sativa genotypes. Can. J. Plant Pathol. 32:416-417.

16. McVay, K. A., and Khan, Q. A. 2011. Camelina yield response to different plant populations under dryland conditions. Agron. J. 103:1265-1269.

17. McVay, K. A., and Lamb, P. F. 2008. Camelina production in Montana. Guide MT200701 AG, Revised 3/08. Montana State University Extension, Bozeman.

18. Okubara, P. A., Schroeder, K. L., and Paulitz, T. C. 2008. Identification and quantification of pathogenic Rhizoctonia solani and $R$. oryzae using realtime PCR. Phytopathology 98:837-847.

19. Plessers, A. G., McGregor, W. G., Carson, R. B., and Nakoneshny, W. 1962. Species trials with oilseed plants. II. Camelina. Can. J. Plant Sci. 42:452-459.

20. Putnam, M. L., Serdani, M., Ehrensing, D., and Curtis, M. 2009. Camelina infected by downy mildew (Hyaloperonospora camelinae) in the western United States: a first report. Plant Health Progress. Online publication. doi:10.1094/PHP-2009-0910-01-BR

21. Robinson, R. G. 1987. Camelina: a useful research crop and a potential oilseed corp. Univ. Minn. Agric. Exp. Stn. Bull. 579.

22. Roeckel-Drevet, P., Tourvieille, J., Drevet, J., Says-Lesage, V., Nicolas, P., and Tourvieille de Labrouhe, D. 1999. Development of a polymerase chain reaction diagnostic test for the detection of the biotrophic pathogen Plasmopara halstedii in sunflower. Can. J. Microbiol. 45:797-803.

23. Saccardo, P. A. 1926. Sylloge Fungorum 24:46.

24. Sackston, W. E. 1981. Downy mildew of sunflower. In: The Downy Mil- dews. D. M. Spencer, ed. Academic Press, London.

25. Séguin-Swartz, G., Eynck, C., Gugel, R. K., Strelkov, S. E., Olivier, C. Y., Li, J. L., Kelin-Gebbenick, H., Brohan, H., Caldwell, C. D., and Falk, K. C. 2009. Diseases of Camelina sativa (false flax). Can. J. Plant Pathol. 31:375386.

26. Shonnard, D. R., Williams, L., and Kalnes, T. N. 2010. Camelina-derived jet fuel and diesel: sustainable advanced biofuels. Environ. Prog. Sustain. Energy 29:382-392.

27. Singh, S. D. 1995. Downy mildew of pearl millet. Plant Dis. 79:545-550.

28. Singh, S. D., and Williams, R. J. 1980. The role of sporangia in the epidemiology of pearl millet downy mildew. Phytopathology 70:1187-1190.

29. Spencer-Phillips, P. T. N., Gisi, U., and Lebeda, A. 2002. Advances in Downy Mildew Research. Kluwer Academic Publishers, Dordrecht, The Netherlands.

30. Thakur, R. P., Rao, V. P., and Sharma, R. 2011. Influence of dosage, storage time and temperature on efficacy of metalaxyl-treated seed for the control of pearl millet downy mildew. Eur. J. Plant Pathol. 129:353-359.

31. Vollmann, J., Steinkellner, S., and Glauninger, J. 2001. Variation in resistance of camelina (Camelina sativa (L.) Crantz.) to downy mildew (Peronospora camelinae Gaum.). J. Phytopathol. 149:129-133.

32. Zarafi, A. B., Emechebe, A. M., and Akpa, A. D., and Alabi, O. 2004. Effect of metalaxyl on the incidence and severity of pearl millet downy mildew disease in Northern Nigeria. Arch. Phytopathol. Plant Prot. 37:261-268.

33. Zarzycka, H., and Kloczowska, T. 1964. Results of investigations on the control of downy mildew of False Flax (Camelina sativa). Biol. Inst. Ochr Rosl. Poznan 26:231-448. 1965 Annu. Rev. Mycol. 44:302.

34. Zarzycka, H., and Kloczowska, T. 1967. Investigations on the control of $P$ parasitica of False Flax. Biol. Inst. Hodowl. Aklim. Rosl. 6:147-159. 1969 Annu. Rev. Mycol. 48:331. 